Please do not remove this page

RMIT

UNIVERSITY

\title{
A quantitative framework for the formation of liquid marbles and hollow granules from hydrophobic powders
}

Eshtiaghi, Nicky; Hapgood, Karen

https://researchrepository.rmit.edu.au/esploro/outputs/9921858351401341/filesAndLinks?institution=61RMIT_INST\&index=null

Eshtiaghi, N., \& Hapgood, K. (2012). A quantitative framework for the formation of liquid marbles and hollow granules from hydrophobic powders. Powder Technology, 223, 65-76.

https://doi.org/10.1016/j.powtec.2011.05.007

Document Version: Accepted Manuscript

Published Version: https://doi.org/10.1016/j.powtec.2011.05.007

Repository homepage: https://researchrepository.rmit.edu.au

(C) 2011 Elsevier B.V. All rights reserved

Downloaded On 2023/04/27 01:28:57 +1000

Please do not remove this page 


\section{Accepted Manuscript}

A quantitative framework for the formation of liquid marbles and hollow granules from hydrophobic powders

Nicky Eshtiaghi, Karen P. Hapgood

PII:

S0032-5910(11)00243-9

DOI: doi: 10.1016/j.powtec.2011.05.007

Reference: $\quad$ PTEC 8310

To appear in: $\quad$ Powder Technology

Received date: 19 January 2011

Revised date: $\quad 6$ May 2011

Accepted date: $\quad 9$ May 2011

Please cite this article as: Nicky Eshtiaghi, Karen P. Hapgood, A quantitative framework for the formation of liquid marbles and hollow granules from hydrophobic powders, Powder Technology (2011), doi: 10.1016/j.powtec.2011.05.007

This is a PDF file of an unedited manuscript that has been accepted for publication. As a service to our customers we are providing this early version of the manuscript. The manuscript will undergo copyediting, typesetting, and review of the resulting proof before it is published in its final form. Please note that during the production process errors may be discovered which could affect the content, and all legal disclaimers that apply to the journal pertain. 


\section{A quantitative framework for the formation of liquid marbles and hollow granules from hydrophobic powders}

Nicky Eshtiaghi ${ }^{1,2}$, Karen P. Hapgood ${ }^{2}$

1- Monash Advanced Particle Engineering Laboratory, Department of Chemical Engineering, Monash University, VIC 3800, Australia

2-School of Civil, Environmental and Chemical Engineering, RMIT University, VIC 3001, Australia Email: Karen.Hapgood@ monash.edu

Email: Now at nicky.eshtiaghi@ rmit.edu.au

\section{Abstract}

Liquid marbles are micro reservoirs of fluid surrounded by a powder shell. Their unique properties show promise for high-value technological applications in the medical, biotechnology, chemical and pharmaceutical industries. In this study, liquid marbles were prepared from six mixtures of water and glycerol by releasing droplets from different heights onto a loosely packed powder bed using a $1 \mathrm{~mL}$ syringe. Pictures of the liquid marbles were taken with a stereo microscope (SMZ series) with a $3 \mathrm{MP}$ Motic camera. The powders used were Aerosil R202, hydrophobic glass ballotini and PTFE spheres.

In this paper, our previous proposed qualitative framework for liquid marble formation via solid spreading coefficient mechanism was updated in light of recent new research and the quantitative criteria for each step was established and validated. The last step of the framework was modified to reflect the physical flow mechanism now understood to be responsible for liquid marble formation. The revised framework presents the step by step process and quantitative criteria for liquid marble formation via a preformed droplet template. In addition, new frameworks for the formation of liquid marbles via the mechanical dispersion regime and for the formation of hollow granules were also 
developed and validated. These frameworks give a better understanding of the mechanisms controlling the granulation of hydrophobic particles to form liquid marbles and provide guidance on how to mass produce liquid marbles and hollow granules.

\section{Graphical Abstract}

The previously proposed qualitative framework for liquid marble formation was updated in light of new research. The revised framework presents the process steps and quantitative criteria for liquid marble formation via a preformed droplet template as well as new frameworks for the mechanical dispersion regime and for hollow granule formation.

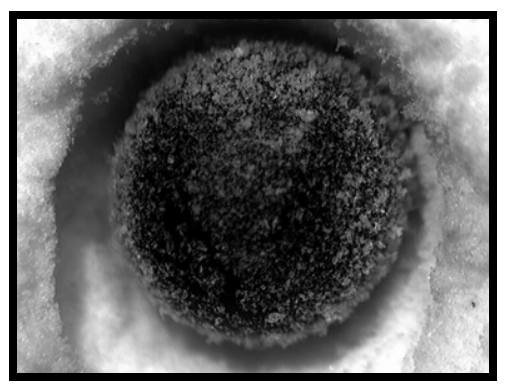

\section{Research Highlights}

- Presents an updated quantitative framework for liquid marble formation

- Formation via drop templates or mechanical dispersion are both covered.

- Contact angle and mixing energy are important parameters

- Framework for hollow granule formation also proposed

Keywords: Liquid marble; hydrophobic granulation; dry water; non-wetting; hollow granule.

\section{Introduction}

"Liquid marbles" are liquid droplets covered with an exterior shell of a hydrophobic powders, and are able to roll and bounce like glass marbles but deform and flex like a fluid [1-2]. Non stick liquid marbles have attracted significant attention of researchers in the past decade, due to their 
promising technological applications [3] in biotechnology [4], chemical and mechanical engineering [4-12], and are already used in several commercial cosmetics [13] (e.g. Dior IOD AquaPowder) and hair care products (e.g. Schwarzkopf Osis powder). Liquid marbles are also promising candidates to be applied in the biomedical and genetic analysis fields where 2D micro fluidics and lab-on-chip methods are used to quickly analyse very small amounts of materials [8, 14-15]. Liquid marbles, also known as "dry water" literally repel water, bounce off after an impact and slip on a surface. Liquid marbles can be used as micro reservoirs, containing up to $98 \% \mathrm{w} / \mathrm{w}$ water [16] which can move quickly without any leakage as the force needed to move these marbles on solid surfaces is extremely small because of the diminished area of liquid-solid contact [6, 14-15, 17].

Single liquid marbles can be prepared by rolling or shaking a single drop of fluid on a bed of fine hydrophobic particles [1]. There are now several studies on liquid marble formation at small scale $[1-3,5-7,11-12,14-15,17-19]$ but few studies on large scale production of liquid marbles using conventional granulation equipment are reported in the literature [16, 20-22]

Aussillous and Quere [1] were the first to report liquid marbles and several studies have focused on the properties of individual liquid marbles, including their robustness and possible methods for setting the marbles in motion [2,18], electrowetting [15], methane storage [23] and gas sensing [9$10]$.

The evaporation rate of the liquid marble is an important parameter to ensure that liquid remains in the marble until it reaches its target location. If the liquid is volatile and evaporates easily, the liquid marble will deform and collapse. The life time of a liquid marble depends on the volatility of 
the fluid, the chemical nature and particle size of the hydrophobic powder, and the powder wall structure. Gao and McCarthy [19] formed ionic liquid marbles by using fluoride containing polymers (OTFE, PTFE), and these ionic liquid marbles remained floating on a water surface for a week, compared to hydrophobic silica liquid marbles which floated for a minute before coalescing. Dandan and Erbil [14] studied the life time of graphite liquid marbles in comparison with water droplets of the same size. They found that graphite liquid marbles more than twice as long as a pure water droplet.

The liquid marble powder wall hinders evaporation of the droplet but is the most poorly understood contributor to the liquid marble lifetime. Investigation of the internal liquid marble structure using confocal microscopy [24] has shown that the liquid marble wall is composed of a combination of mono and multi layers of particles. Coarse particles (above 50 microns in size) formed mono layers, while fine particles formed a multi-layered powder shell. Bhosale et al. [25] also reported that cohesive powders were more likely to form a multi-layer of particles on the liquid surface. Nguyen et al. [24] found that the extent of penetration of coarse particles into the liquid core was much less than fine particles. Larger particles tend to float on the top of the liquid core instead of submerging into the liquid core.

In our previous paper [26], a preliminary framework for liquid marble formation was proposed for formation of a stable, spherical, liquid marble from a single drop via "solid spreading nucleation" [22]. The final step of the framework postulated that the liquid marble formation was most likely driven by surface energy and could be described by the solid over liquid spreading coefficient, $\lambda_{\mathrm{SL}}$ 
[27]. However, a fresh thermodynamic analysis [28] and calculations [29] of the existing solid-liquid spreading coefficient revealed that the existing solid-liquid spreading coefficient theory is not able to predict whether a liquid marble will form. Instead, a proportional relationship was found between kinetic energy and the percentage of liquid marble coverage, demonstrating that the kinetic energy of impact is responsible for formation of liquid marbles [29]. The shell appears to be formed by a physical flow mechanism during drop impact. The kinetic energy from impact causes an increase in drop surface area due to the drop deformation. The subsequent drop recoil creates fluid flow which entrains the powder and forms the powder shell [30-31]. Increasing the drop release height (and therefore increasing the kinetic energy of impact) increases the liquid marble powder coverage.

McEleney et al. [32] also found that kinetic energy is required for liquid marble formation, and reported that the surface coverage decreases with increasing particle size. If the particle size is large, the kinetic energy of shaking or rolling the drop may not produce enough kinetic energy to entrain the large particles on the liquid surface. More vigorous agitation (such as mixing in a granulator) would be required for complete surface coverage.

These results supported separate, parallel observations of the role of mixing intensity during large scale production of liquid marbles. In a series of related papers, Forny et al. [16, 21, 33-34] reported powder encapsulation of water with different level of hydrophobicity fumed silica powder (Aerosil R972, R812S) in two different vertical axis mixers - a "high shear" mixer with knife blades and a "low" shear Triaxe mixer with rotating gyrating paddles. They also concluded that the kinetic energy is the key to liquid marble formation [16]. Forny et al. used two alternate methods to add water to the silica powder: direct loading of the liquid and powder into the mixer prior to 
commencing mixer operation; and by atomization over 3-4 minutes. In the low shear Triaxe mixer, atomization was required to form liquid marbles but they collapsed quickly to form a foam or mousse. The high shear mixer was more successful and liquid marbles formed very quickly (approx 10 seconds). Using the more hydrophobic silica powder (R812S) and high shear processing conditions, up to $98 \% \mathrm{w} / \mathrm{w}$ water was able to be encapsulated with powder in the high-shear mixer. Formation of stable silica covered drops was most effective at the speeds of $12000 \mathrm{~min}^{-1}$ or higher in the high shear mixer with knife-edged impeller blades. Below this speed, the water formed a puddle at the base of the bowl and could not be successfully dispersed through the powder. Atomization into the high-shear mixer was not attempted. As the hydrophobicity of the silica powder decreased, the system became less stable, requiring lower impeller speed and more powder to encapsulate the same volume of liquid. Less hydrophobic silica powders were also more sensitive to shear conditions and collapse of the liquid marbles into a foam or mousse was reported [21]. The time for collapse reduced as the impeller speed and applied shear increased.

Binks and Murakami [35] also studied the transformation of particle-stabilized aqueous foam into water-in-air powder (dry water) and vice versa in a system of air, water and fumed silica nanoparticles with different degrees of hydrophobicity. The inversion of the air-water-particles system could be achieved in two ways: (i) changing the particle hydrophobicity at constant air/water ratio; or (ii) changing the air/water ratio at fixed particles wettability (Figure 1). If more fluid is added to a group of liquid marbles (without also adding more powder), the liquid will gradually excluded the air and the resulting phase inversion will create a mousse at high liquid contents. 
Forny et al. summarized the investigated the effect of powder hydrophobicity and several process variables on the formation of the powder encapsulated liquid and developed a regime map (which they termed a "state diagram") [34] shown in Figure 2, which predicts the formation of three types of final products as a function of the contact angle of the system and the energy per unit mass applied to the process $\mathrm{E}_{\mathrm{p}}$. If insufficient energy is applied during mixing, the liquid and powder remains as two separate phases. The applied energy per unit mass must be above a certain minimum threshold $\left(\mathrm{E}_{\mathrm{p}}\right)_{\min }$ for the liquid to be effectively dispersed through the powder to form liquid marbles. However, further increases in the energy applied per unit mass eventually exceed a maximum energy threshold $\left(\mathrm{E}_{\mathrm{p}}\right)_{\max }$, which causes the liquid marbles to collapse into a foam or mousse. For liquid marble formation, the energy applied per unit mass $\mathrm{E}_{\mathrm{p}}$ should be between $\left(\mathrm{E}_{\mathrm{p}}\right)_{\min }$ and $\left(\mathrm{E}_{\mathrm{p}}\right)_{\max }$ [34]. The quality of final product at very high contact angle (in the right part of the diagram) is uncertain. The map also summarises that liquid marble formation in highly energetic processes such as highshear blenders requires highly hydrophobic particles to avoid forced immersion of the particles into the fluid, and while lower energy processes can use moderately hydrophobic particles.

In all of the studies discussed so far, the liquid marbles were the desired end product. Hapgood et al [22] was the first researcher who dried liquid marbles to form hollow granules at a larger scale although McEleney et al. [32] later reported the formation of a hollow granule shell after polymerising individual poly-methylmethacralate (PMMA) liquid marbles. In both cases, the final product of hollow granules was obtained by removing the interior liquid i.e. the formation of liquid marbles represents an intermediate product. "Designer" granules with a controlled hollow internal structure are ideal for high-value applications in the pharmaceutical, food and cosmetic industries. 
Hapgood et al. [22] produced hollow granules in a $2 \mathrm{~L}$ granulator using a formulation of $70 \mathrm{wt} \%$ of a hydrophobic drug powder, $20 \%$ microcrystalline cellulose and $4 \%$ hydroxypropyl cellulose binder as hydrophilic excipients plus $1 \%$ sodium lauryl sulfate surfactant (added dry to the powder blend). The hollow granules were strong enough to withstand the downstream milling process as the excipients stabilized the powder shell to allow the hollow structure to be preserved during drying.

A follow-up study of large scale production of liquid marbles and hollow granules [20] investigated the effect of liquid to powder mass ratio on the morphology and particle size distribution of hollow granules. Marbles were formed by spraying a HPC binder solution onto hydrophobic silica (Aerosil R202). The optimum L:S ratio was defined as the point where the raw fine particles were granulated but fewer flattened or stretched hollow granules were produced. If the nucleation process starts with a preformed template droplet (e.g. spraying liquid), the final granule size increases and the amount of un-granulated fine particles decreases as the L:S ratio increases. In contrast, Forny et al. [16, 21, 33-34] used the shear forces generated by the impeller to disperse the liquid through the powder, and they found no effect of L:S ratio on particle size. This implies that the effect of the liquid to solid ratio varies, depending on whether the fluid is atomised to form discrete drop templates, or added in bulk where an agitator disperses the fluid through the powder.

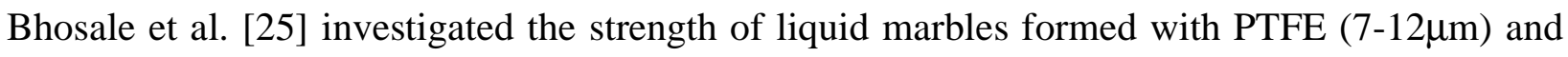
two types of treated fumed silica powder. High surface area nano-particles (e.g. Aerosil) created more uniform powder shells through uniform coverage of the liquid-vapour interface. These nanopowder shells formed an "elastic" membrane that made the liquid marbles mechanically robust in comparison with conventional liquid marbles, as they were able to withstand higher compressive 
stresses during drying. This work suggests that nano-powders may be more likely to successfully form hollow granules.

Drying temperature is also an important variable when forming stable hollow granules from a liquid marble precursor [36]. Higher drying temperature, smaller or nano-sized particles and higher binder concentration tended to promote the formation of spherical hollow granules. The hollow granule survival rate was directly proportional to binder viscosity for HPMC and PVP. However for HPC binder, the survival rate was essentially constant regardless of HPC concentration due to precipitation of the HPC binder above the cloud point temperature $\left(45^{\circ} \mathrm{C}\right)[36]$.

This paper updates and validates the qualitative preliminary framework for liquid marble formation proposed previously [26], incorporating the more recent knowledge generated by several recent studies of liquid marble formation. Quantitative criteria for each step are determined and validated with the best data currently available. In addition, we extend the framework to cover the additional required steps for the formation of liquid marbles via mechanical dispersion, linking work by separate research teams, and propose a new qualitative framework for the formation of hollow granules from liquid marbles.

\section{Materials and Methods}

Glass ballotini spheres $\left(\rho=2.5 \mathrm{~g} / \mathrm{cm}^{3}\right.$, Potters Industries Pty Ltd.) in three size grades (AC, AE, AG/AH with 191, 121, $65 \mu$ m mean particle size, respectively) were used to form liquid marbles. In order to make the glass beads hydrophobic, SIGMACOTE solution (chlorinated organopolysiloxane in heptane, Sigma Aldrich Pty Ltd.) was used. Two additional hydrophobic powders were used: 
Polytetra fluoroethylene (PTFE) with four different particle size grades $(1,12,35$, and $100 \mu \mathrm{m}$, $\rho=2.1 \mathrm{~g} / \mathrm{cm}^{3}$, Sigma Aldrich Pty Ltd), and fumed silica Aerosil R202 with a primary particle size of $16 \mathrm{~nm}$ (Degussa, Germany).

Several different binder solutions were used: Distilled water, poly-ethylene glycol (PEG200, Sigma Aldrich Pty Ltd). and six solutions of distilled water and glycerol (99\%, Sigma Aldrich Rieldel-deHaen). Food dye was added to the glycerol solutions to assist with visual observations. (See reference [29] for fluid properties),

Liquid marbles were prepared by releasing individual droplets from a $1 \mathrm{~mL}$ syringe with a $18 \mathrm{~g}$ needle approximately $2 \mathrm{~cm}$ above a loosely packed powder bed [29]. The droplet volumes varied depending on the fluid used, and the drop diameters are given in Table 1. Additional experiments were performed by releasing a droplet from different heights on a powder bed to investigate the effect of kinetic energy and to validate the dimensionless groups predicting drop shattering. Pictures of the liquid marbles after impact were taken with a stereo microscope (SMZ series) with a 3MP Motic camera [29].

\section{Results and Discussion}

\subsection{Droplet and particle size}

To form a liquid marble, the preliminary framework [26] proposed that each drop must be much larger than the size of the primary powder particles (i.e. $d_{d}>>d_{p}$ ) in order for the particle to spread around the droplet template. The question is: to what extent must the droplet size be larger than the particle size? Experimental and literature data were reviewed to find the quantitative correlation 
between droplet size and particle size. Table 1 summarizes the actual droplet and particle sizes that were used in both our previous studies $[20,26,29,36]$ and other studies of liquid marble formation in literature $[1,14,16,19,25,32,35]$. Table 1 shows that for a wide range of powder and liquid combinations, a liquid marble forms if the droplet diameter is at least 25 times of the particle diameter. Therefore, the first step of the framework was modified to include the precise ratio of droplet diameter to particle diameter, $d_{d}>25 d_{p}$, as presented in Figure 3.

Figure 3 also shows all the other modifications to the framework which will be discussed in this paper. Figure 3 applies only to droplet-template controlled liquid marble formation. Formation in the mechanical dispersion regime will be discussed later.

Note that the particle size presented in Table 1 is the reported primary particle size. In practice, several of these powders were aggregated. For example, the reported manufactured particle size for Aerosil used in several studies [20-21, 25] is $12-16 \mathrm{~nm}$, but this powder is tend to self-agglomerate to form large and loose networks with a much larger particle size between 1 to $30 \mu \mathrm{m}$. Graphite powder has a primary particle size of 2 to $30 \mu \mathrm{m}$ but $60 \%$ of the graphite was aggregated in clusters between 10 and $20 \mu \mathrm{m}$ [14]. PTFE 1, PTFE 12, and PTFE 35 with reported particle size of 1, 12 and $35 \mu \mathrm{m}$, respectively [29], were also noted to agglomerate although the agglomerate particle size was not measured. Since the role (if any) of the powder aggregates is not known, we have used the primary particle size as the reference particle size.

\subsection{Dimensionless groups for drop impact and shattering}

In addition to the requirement that the droplet size be at least 25 times the particle size, the droplet size must also be small enough to form a spherical drop on powder bed rather than a distorted pool 
or puddle. For this reason, the next step of liquid marble formation flow chart is Bond number Bo (Eq. 1), which represents the ratio of surface tension and gravity forces. The Bond number has been shown by several groups to accurately predict whether a liquid marble will be spherical $[1-2,17,32]$.

$$
B o=\frac{\rho g R^{2}}{\gamma}
$$

If the Bond number is below one, the surface tension forces dominate and the droplet is pulled into a spherical shape liquid marble (refer to Figures 5 and 6). If the Bond number is above one, the droplet forms a puddle shape on a powder bed surface [2]. Figure 4 shows a puddle shaped PEG200 liquid marble on a bed of hydrophobic glass beads with $B o=1.14$.

Ideally, the drop should land on the powder and survive the impact without breaking or shattering into smaller satellite droplets. Previous studies [37-38] suggested that drop shattering could be predicted using the Weber number We (equation 2) and the Ohnesorge number $O h$ (equation 3)

$$
\begin{aligned}
& W e=\frac{\rho_{L} d_{d} v^{2}}{\gamma_{L V}} \\
& O h=\frac{\mu}{\left(\rho_{L} \gamma_{L V} R\right)^{0.5}}
\end{aligned}
$$

These papers suggested that the critical criteria to prevent breakage were $W e<1000$ and $O h>0.05$ [37-38]. A more recent study looked at the effect of packing fraction on drop impact behaviour and found that the Weber number should be less than 750 to avoid shattering [39]. Table 2 presents the calculated value of Bond number Bo, Weber number We and Ohnesorge number $O h$ for the experimental data in a previous study [29] and indicates whether the drop shattered or remained intact after impact on the powder surface. Figures 5 and 6 show several examples of conditions in 
Table 2 where droplets survived impact without shattering. Figure 7 shows two examples of shattered droplets where the $W e>1000$.

Generally, the data in Table 2 supports the $W e<1000$ limit [37-38] to prevent drop shattering. However, the additional criteria of $O h>0.05$ to prevent shattering [38] is not consistent with the experimental results. There are several cases in Table 2 where $O h$ was below 0.05 , but the droplet did not break because the Weber number was below the critical limit of 1000. For example, a 3.4 mm 20\% glycerol solution drop released on PTFE100 from $15 \mathrm{~cm}$ survived even though $O h$ was far less than 0.05 ( $W e=159$ and $O h=0.003$ ). See also images (a) to (e) in Figure 4 where $O h<0.05$ but the drop did not shatter after impact. Table 2 also contains data where the Weber number predicts shattering but the Ohnesorge number does not (i.e. where $W e>1000$ but $O h>0.05$ ). In these cases, the droplet shattered (e.g. $3 \mathrm{~mm}$ water droplet on glass beads (AG) with $W e=3000$ and $O h=0.08$ ).

The drop shattering behaviour is also summarized in Figure 9 which plots $O h$ versus We and indicates whether the drop shattered into smaller satellite droplets on impact (filled symbols) or survived intact. Figure 9 clearly shows that the Weber number criterion of $W e>1000$ successfully predicts that the drop will shatter after impact. In contrast, the value of $O h$ does not appear to be predictive at all.. Thus, the $O h$ number can be removed from the liquid marble formation framework. Based on our experimental data, the revised framework (Figure 3) recommends $W e<1000$ to prevent drop shattering, which is in agreement with the earlier conclusions [37]. There is little data between $750<W e<1000$ to support dropping the limit to 750 in line with the most recent study [39], and the role of the powder packing fraction [39] on drop impact and liquid marble formation is an area for future work 


\subsection{Contact angle}

Stable liquid marbles are formed from hydrophobic powders, since the fluid must have a contact angle $\theta$ greater than $90^{\circ}$ with the powder to prevent penetration of the drop into pores of the powder bed. Table 3 presents the contact angle of various powders based on the values reported in the literature. Direct data for Aerosil R202 is not available. However, Forny et al. [16] reported the following ranking for different grades of fumed silica in order of increasing hydrophobicity:

$$
\mathrm{R} 711<\mathrm{R} 972<\mathrm{R} 812 \mathrm{~S}<\mathrm{R} 202
$$

The contact angle for R812S is $113^{\circ}$ [34]. Thus, we conclude that Aerosil R202, which is the most hydrophobic silica powder, has a contact angle larger than $113^{\circ}$. Table 3 shows that all reviewed studies of liquid marble formation have used a powder and liquid with a contact angle above $90^{\circ}$ and this is shown as the fourth criterion in the framework in Figure 3.

\subsection{Spray flux}

In order to maintain small individual drop templates, the dimensionless spray flux must be low [40] or else there will be significant drop overlap. Under low spray flux conditions $\left(\Psi_{\mathrm{a}}<0.1\right)$, each drop would be sufficiently separated from the other drops to form a single liquid marble. Under these conditions, the marble size distribution would be almost identical to the atomized drop size distribution, i.e. the drop controlled nucleation regime [41]. The original framework [26] suggested $\Psi_{\mathrm{a}}<0.1$ and assumed that nucleation of liquid marbles occurred only in the drop controlled regime. However, recent studies of liquid marble production have shown that the production of liquid marbles via mechanical dispersion $\left(\Psi_{\mathrm{a}}>1\right)$ is also possible. Forny et al. $[16,21,34]$ did not atomise 
at all in several experiments and the calculated value of dimensionless spray flux in our previous experiments [20] was in fact greater than one $\left(\Psi_{\mathrm{a}} \sim 1.4\right)$. Despite this, no obvious puddle formation or adverse affect on liquid marble formation phenomena was observed. However, deformed, stretched and foam-like multi-cavity hollow granules were formed instead of individual spherical hollow granules containing a single cavity [20]. Thus it is possible to form liquid marbles via mechanical dispersion of the fluid, although single cavity hollow spheres with the same size distribution as the spray are still are expected to be promoted by low spray flux conditions. Liquid marble formation in the mechanical dispersion regime is discussed in more detail in section 3.6.

\subsection{Role of kinetic energy in liquid marble formation}

Originally, the final step of the preliminary framework for liquid marble formation [26] was provisionally shown as needing a positive value of the solid-over-liquid spreading coefficient $\lambda_{S L}$. The hypothesis of whether the solid-liquid spreading coefficient $\lambda_{S L}$ predicts liquid marble formation has now been tested [29] by calculating the solid-liquid spreading coefficient $\lambda_{S L}$ and comparing with the experimental results. The calculated solid-liquid and liquid-solid spreading coefficients for several liquid marble formulations demonstrated that the spreading coefficient theory is inconsistent with experimental observations of liquid marble formation [29] and with thermodynamic principles [28]. Instead, several independent studies have observed the importance of kinetic energy in liquid marble formation, $[16,21,29,32,34]$. Therefore, the solid-liquid spreading coefficient has been removed from the framework and replaced with the kinetic energy criterion as presented in Figure 3. 
In addition, Forny et al. [34] demonstrated that the energy applied per unit mass of powder $\left(\mathrm{E}_{\mathrm{p}}\right)$ is a critical parameter during liquid marble formation. The energy must be above the minimum threshold energy $\left(E_{p}\right)_{\min }$ or the particles and the fluid will remain as a separate phase, but below the maximum threshold energy $\left(\mathrm{E}_{\mathrm{p}}\right)_{\max }$ where a mousse will be generated. Binks and Murakami [35] also noted the possibility of phase inversion to form a foam. No bulk phase inversion was observed in our previous study [20] in the mechanical dispersion regime, although some larger granules with foam-like structure were observed. We could not determine whether these foam-like granules were due to localized areas of phase inversion to form a mousse or due to coalescence of liquid marbles in the high spray flux spray zone.

Therefore, the final step of the liquid marble formation flow charts is that the energy applied to the system must be within the optimal energy range. The new step specifies that $\left(E_{p}\right)_{\min }<\left(E_{p}\right)<\left(E_{p}\right)_{\max }$, as shown in Figure 3. This step is also shown (separately) in the mechanical dispersion flow sheet.

\subsection{Mechanical Dispersion Framework}

Several papers have been published where the liquid was dispersed by mechanical dispersion [16, $20,34]$. In the mechanical dispersion regime, where the liquid is added in bulk [16, 34] or the spray has $\Psi_{\mathrm{a}}>1$ [20] liquid marble formation is still possible provided that the fluid has a contact angle $\theta$ greater than $110^{\circ}$ [34] as the highly energetic conditions during powder agitation can lead to the immersion of moderate hydrophobic particles into the liquid phase [34]. 
Figure 9 summarizes the steps required for formation of liquid marbles in the mechanical dispersion regime. The contact angle needs to be above $110^{\circ}$ and $\mathrm{E}_{\mathrm{p}}$ must be between the upper and lower threshold energy limits [34], as discussed in section 3.5. The final step is that under high shear conditions and turbulent liquid flow, the bulk liquid is divided in stable droplets. We assume that the droplet size must also be 25 times larger than particle size; otherwise, no spreading of particles around the droplet can occur.

Figure 10 integrates Figures $3 \& 9$, and shows how liquid marbles can be formed via the droptemplate controlled method or via the mechanical dispersion method. This framework provides a useful overview of the research to date and is expected to aid future liquid marble research as well as trouble shooting mass production of liquid marbles.

\subsection{Hollow granule formation}

In order to form a hollow granule, the powder shell must be sufficiently strong and self supporting in order to avoid collapse during the drying process and subsequent standard powder handling operations [26]. Figure 11 outlines the series of steps we believe are required for the formation of a stable hollow granule from a liquid marble precursor. Although direct polymerisation of the shell is possible [32] we consider here the case where a polymeric binder is used to avoid the liquid marble collapsing during drying. The polymeric binder forms solid bridges between the particles during drying which give strength to the powder shell $[22,36]$. The final morphology of a spray dried hollow sphere depends on chemical and physical nature of the skin material [42]. Polymeric materials tend to form a porous skin that can help the formation of hollow particles during the drying period without any rupture or deflation [42]. Experimental results [36] showed that all of the hollow 
granules formed without polymeric binder in the formulation collapsed, as expected. Thus, the first step in hollow granule formation is the existence of a polymeric binder in the formulation.

The next step in the successful formation of hollow granules is controlled by compatibility of the polymeric binder with the chemical and physical properties of the powder. For example, previous experimental results [36] showed that HPMC was the most compatible polymeric binder with all the powders used while the use of PVP as a binder resulted in the complete collapse of all hollow granules at all the drying temperatures tested. Binder behaviour is a complex function of chemistry, rheology and other factors, including the cloud point, and cannot be fully described or quantified at this stage [36].

There is also a minimum polymeric binder concentration needed in the formulation to provide enough mechanical strength to the sphere as it dries [36]. Increasing the concentration of polymeric binder is known to reduce particle distortion and surface rupture [42]. There was a proportional relationship between binder fluid viscosity (which is related to concentration of binder) and the proportion of hollow granules formed when PVP and HPMC were used as the binder [36]. However for HPC binder, the survival rate remained constant regardless of the HPC concentration, presumably due to precipitation of HPC above the cloud point [43].

The next step in the hollow granule formation flow chart (Figure 11) is selecting the optimum liquid to solid ratio during granulation. The optimal liquid to solid ratio for any granulation processes must currently still be determined by trial and error and cannot be predicted in advance. However, the L:S 
ratio required for liquid marbles and generally lies between approximately 1:1 to 6:1 (see Table 4). In contrast, conventional granulation typically uses liquid to solid ratios around 0.3 to $0.5: 1$. Choosing the optimal L:S ratio is important for maximising the number of spherical, single cavity granules and minimising the formation of foam sheets $[20,35]$. In practice, the optimum L:S ratio is not as simple to define, and has been defined as the liquid ratio where the final product contains the least ungranulated fine particles and the minimum number of flattened or foam-like hollow granules are produced [20].

The liquid to solid ratio data from small scale single drop studies has not been considered, as this data can be difficult to measure and the ratio at small scale does not necessarily extrapolate to the same ratio at full scale commercial production. It is not currently known whether the powder shell structure and thickness is the same or different for liquid marbles formed from a single drop, compared to liquid marbles formed in bulk via a spray.

The final criteria established for formation of hollow granules is the drying temperature, which is as important as the polymeric binder concentration in determining whether a hollow spherical granule is formed. As an example, hollow granules formed from glass ballotini survived if the drying temperature was above $80^{\circ} \mathrm{C}$ while Aerosil granules survived as long as the drying temperature was above $60{ }^{\circ} \mathrm{C}$ [36]. This implies that there is a different minimum temperature requirement for various powder/binder combinations in order to form a hollow granule. In general, increasing temperature increases the survivability and improves the quality of hollow granules, although HPC binders do not follow this trend [36]. 
Figure 11 illustrates each of the qualitative criteria we believe to be necessary to convert a liquid marble formulation into a stable hollow granule. Each step in this framework requires further investigation to determine more specific quantitative criteria and to validate them.

\subsection{Conclusion}

In this paper, the preliminary flow chart for liquid marble formation proposed previously [26] was revised and validated in light of new knowledge.. A revised flow chart for the formation of liquid marbles via the "droplet template" regime was presented. In addition, the flowsheet was extended to include the formation of liquid marbles via the "mechanical dispersion" regime. The main differences between droplet template regime and mechanical dispersion regime are the contact angle and spray flux requirements. When spray flux becomes greater than one, granulation switches from droplet template regime to mechanical dispersion regime. Liquid marbles can form successfully in the mechanical dispersion regime if the contact angle is above $110^{\circ} \mathrm{C}$. This is higher than the $90^{\circ}$ angle required for the drop template framework, as the particles must be more hydrophobic in the mechanical dispersion regime in order to resist immersion into the fluid, destroying the liquid marbles.

In addition, a qualitative framework for the formation of hollow granules was proposed which emphasizes the importance of the finding a compatible polymeric binder and identifying the optimum binder concentration, L:S ratio and drying temperature. However, the hollow granule framework proposed here required further work to quantify and validate the criteria in each step. 
These frameworks give a better understanding of the controlling mechanisms in the granulation of hydrophobic particles and provide guidance on how to mass produce liquid marbles and hollow granules.

\section{Acknowledgements}

This project was financially supported by the Australian Research Council under Discovery Projects DP0770462. Scholarship support for N. Eshtiaghi was provided by the Monash Graduate Research School. 


\section{References}

1. $\quad$ Aussillous, P. and D. Quere, Liquid marbles. Nature, 2001. 411(6840): p. 924-927.

2. Aussillous, P.J. and D. Quere, Properties of liquid marbles. Proceedings Royal Society A, 2006. 462(2067): p. 973-999.

3. McHale, G. and M.I. Newton, Liquid marbles: principles and applications. Soft Matter, 2011. DOI: $10.1039 / \mathrm{c} 1 \mathrm{sm} 05066 \mathrm{~d}$.

4. Dorvee, J.R., M.J. Sailor, and G.M. Miskelly, Digital microfluidics and delivery of molecular payloads with magnetic porous

silicon chaperones. Dalton Transactions, 2008. 6: p. 721-730.

5. Bormashenko, E., R. Balter, and D. Aurbach, Micropump based on liquid marbles. Applied Physics Letters, 2010. 97(9).

6. Bormashenko, E. and A. Musin, Revealing of water surface pollution with liquid marbles. Applied Surface Science, 2009. 255(12): p. 6429-6431.

7. Dupin, D., S.P. Armes, and S. Fujii, Stimulus-responsive liquid marbles. Journal of the American Chemical Society, 2009. 131(15): p. 5386-5387.

8. McHale, G., S.J. Elliott, M.I. Newton, D.L. Herbertson, and K. Esmer, Levitation-Free Vibrated Droplets: Resonant Oscillations of Liquid Marbles. Langmuir, 2009. 25(1): p. 529-533.

9. Tian, J.F., T. Arbatan, X. Li, and W. Shen, Liquid marble for gas sensing. Chemical Communications, 2010. 46(26): p. 4734-4736.

10. Tian, J.F., T. Arbatan, X. Li, and W. Shen, Porous liquid marble shell offers possibilities for gas detection and gas reactions. Chemical Engineering Journal, 2010. 165(1): p. 347-353.

11. Xue, Y., H. Wang, Y. Zhao, L. Dai, L. Feng, X. Wang, and T. Lin, Magnetic liquid marbles: A "precise" miniature reactor. Advanced Materials, 2010. 22(43): p. 1-5.

12. Zhao, Y., J. Fang, H. Wang, X. Wang, and T. Lin, Magnetic liquid marbles: Manipulation of liquid droplets using highly hydrophobic Fe3O4 nanoparticles. Advanced Materials, 2010. 22(6): p. 707-710.

13. S. Hasenzahl, A. Gray, E. Walzer, and A. Braunagel, Dry Water for the Skin. SÖFW-Journal, 2005. 131(3): p. 2-8.

14. Dandan, M. and H.Y. Erbil, Evaporation Rate of Graphite Liquid Marbles: Comparison with Water Droplets. Langmuir, 2009. 25(14): p. 8362-8367.

15. McHale, G., D.L. Herbertson, S.J. Elliott, N.J. Shirtcliffe, and M.I. Newton, Electrowetting of nonwetting liquids and liquid marbles. Langmuir, 2007. 23(2): p. 918-924.

16. Forny, L., K. Saleh, I. Pezron, L. Komunjer, and P. Guigon, Influence of mixing characteristics for water encapsulation by self-assembling hydrophobic silica nanoparticles. Powder Technology, 2009. 189(2): p. 263-269.

17. Quere, D. and P. Aussillous, Non-stick droplets. Chemical Engineering \& Technology, 2002. 25(9): p. 925-928.

18. Dorvee, J.R., A.M. Derfus, S.N. Bhatia, and M.J. Sailor, Manipulation of liquid droplets using amphiphilic, magnetic one-dimensional photonic crystal chaperones. Nature Materials, 2004. 3(12): p. 896-899.

19. Gao, L.C. and T.J. McCarthy, Ionic liquid marbles. Langmuir, 2007. 23(21): p. 1044510447.

20. Eshtiaghi, N., B. Arhatari, and K.P. Hapgood, Producing hollow granules from hydrophobic powders in high-shear mixer granulators. Advanced Powder Technology, 2009. 20(6): p. 558-566. 
21. Forny, L., I. Pezron, K. Saleh, P. Guigon, and L. Komunjer, Storing water in powder form by self-assembling hydrophobic silica nanoparticles. Powder Technology, 2007. 171(1): p. 15-24.

22. Hapgood, K.P., L. Farber, and J.N. Michaels, Agglomeration of hydrophobic powders via solid spreading nucleation. Powder Technology, 2009. 188(3): p. 248-254.

23. Wang, W.X., C.L. Bray, D.J. Adams, and A.I. Cooper, Methane storage in dry water gas hydrates. Journal of the American Chemical Society, 2008. 130(35): p. 11608-+.

24. Nguyen, T.H., W. Shen, and K.P. Hapgood, Observation of the Liquid Marble Morphology using Confocal Microscopy. Chemical Engineering Journal, 2010. 162: p. 396-405.

25. Bhosale, P.S., M.V. Panchagnula, and H.A. Stretz, Mechanically robust nanoparticle stabilized transparent liquid marbles. Applied Physics Letters, 2008. 93(3).

26. Hapgood, K.P. and B. Khanmohammadi, Granulation of hydrophobic powders. Powder Technology, 2009. 189(2): p. 253-262.

27. Rowe, R.C., Binder-substrate interactions in granulation: a theoretical approach based on surface free energy and polarity. International Journal of Pharmaceutics, 1989. 52: p. 149-154.

28. Nguyen, T.H., N. Eshtiaghi, K.P. Hapgood, and W. Shen, An analysis of the thermodynamic conditions for solid powder particles spreading over liquid surface. Powder Technology, 2010. 201(3): p. 306-310.

29. Eshtiaghi, N., J.S. Liu, W. Shen, and K.P. Hapgood, Liquid marble formation: Spreading coefficients or kinetic energy? Powder Technology, 2009. 196(2): p. 126-132.

30. Mahadevan, L. and Y. Pomeau, Rolling droplets. Physics Fluids, 1999. 11: p. 2449-2453.

31. Fujimoto, H. and N. Hatta, Deformation and rebounding processes of a water droplet impinging on a flat surface above leidenfrost temperature. Journal of Fluids EngineeringTransactions of the Asme, 1996. 118(1): p. 142-149.

32. McEleney, P., G.M. Walker, I.A. Larmour, and S.E.J. Bell, Liquid marble formation using hydrophobic powders. Chemical Engineering Journal, 2009. 147(2-3): p. 373-382.

33. Forny, L., K. Saleh, I. Pezron, L. Komunjer, and P. Guigon. Influence of mixing process characteristics for aqueous encapsulation by silica nanoparticles. in World Congress Particle Technology 5. 2006. Lake Buena Vista, Florida, USA: AIChE.

34. Forny, L., I. Pezron, and K. Saleh. Dry water: From physico-chemical aspects to process related parameters. in 9th International Symposium on Agglomeration. 2009. Sheffield UK: Sheffield University.

35. Binks, B.P. and R. Murakami, Phase inversion of particle-stabilized materials from foams to dry water. Nat Mater, 2006. 5(11): p. 865-869.

36. Eshtiaghi, N., J.J.S. Liu, and K.P. Hapgood, Formation of hollow granules from liquid marbles: Small scale experiments. Powder Technology, 2010. 197(3): p. 184-195.

37. Agland, S. and S.M. Iveson. The Impact of Liquid Drops on Powder Bed Surfaces. in CHEMECA 99. 1999. Newcastle, Australia: IEAust/IChemE/RACI.

38. Bartolo, D., C. Josserand, and OTHERS, Retraction dynamics of aqueous drops upon impact on non-wetting surfaces. Journal of Fluid Mechanics, 2005. 545: p. 329-338.

39. Marston, J.O., S.T. Thoroddsen, W.K. Ng, and R.B.H. Tan, Experimental study of liquid drop impact onto a powder surface. Powder Technology, 2010. 203(2): p. 223-236.

40. Litster, J.D., K.P. Hapgood, J.N. Michaels, A. Sims, M. Roberts, S.K. Kameneni, and T. Hsu, Liquid distribution in wet granulation: dimensionless spray flux. Powder Technology, 2001. 114(13): p. 32-39.

41. Hapgood, K.P., J.D. Litster, and R. Smith, Nucleation Regime Map for Liquid Bound Granules. AIChE Journal, 2003. 49(2): p. 350-361. 
42. Walton, D.E. and C.J. Mumford, The morphology of spray-dried particles - The effect of process variables upon the morphology of spray-dried particles. Chemical Engineering Research \& Design, 1999. 77(A5): p. 442-460.

43. Winnik, F.M., Effect of temperature on aqueous-solutions of pyrene-labelled

(hydroxypropyl)cellulose. Macromolecules, 1987. 20(11): p. 2745-2750.

Figure 1: Phase inversion of foams (air-in-water) to Liquid Marble (water-in-air) (Adapted from [35])

Figure 2. State diagram for liquid marble formation as a function of the contact angle and the energetic contribution $E_{p}$ of the process (a) the position of $E_{p}$ for blenders, (b) the position of $E_{p}$ for granulators [34]

Figure 3: Revised framework for the formation of liquid marbles via the droplet template regime

Figure 4: Puddle form of 4 mm PEG200 droplet on hydrophobic glass beads (AG), Bo=1.14

Figure 5: Survived and spherical $3.4 \mathrm{~mm}(\mathrm{a})$ water $(\mathrm{Bo}=0.48, \mathrm{We}=76, O h=0.002)(\mathrm{b}) 20 \%$ glycerol $(\mathrm{Bo}=0.5, \mathrm{We}=106, \mathrm{Oh}=\mathbf{0 . 0 0 3})(\mathrm{c}) 40 \%$ glycerol $(\mathrm{Bo}=0.54, \mathrm{We}=112, O h=0.005)(\mathrm{d})$ $60 \%$ glycerol $(\mathrm{Bo}=\mathbf{0 . 5 8}, \mathrm{We}=101, \mathrm{Oh}=\mathbf{0 . 0 0 9})(\mathrm{e}) \mathbf{8 0 \%}$ glycerol $(\mathrm{Bo}=0.6, \mathrm{We}=137, \mathrm{Oh}=0.02)(\mathrm{f})$ $100 \%$ glycerol $(\mathrm{Bo}=\mathbf{0 . 8 8}, \mathrm{We}=35, \mathrm{Oh}=1.08)$ droplet released from $10 \mathrm{~cm}$ height on PTFE 100 powder bed 
Figure 6: Survived and spherical $3.4 \mathrm{~mm}$ water droplet released from $10 \mathrm{~cm}$ height on (a)

PTFE 1 (b) PTFE 12 (c) PTFE 35, Bo=0.48, We $=113$, Oh= 0.003

Figure 7: Shattered (a) $3.4 \mathrm{~mm} 80 \%$ glycerol droplet released from $75 \mathrm{~cm}(\mathrm{Bo}=0.6, \mathrm{We}=1094$, $O h=0.02)$ and (b) $3 \mathrm{~mm}$ water droplet released from $80 \mathrm{~cm}$ release height $(\mathrm{Bo}=0.3, \mathrm{We}=3000$, $O h=0.08)$ onto hydrophobic glass bead (AG). Arrows indicate the satellite drops produced after the original droplet shattered.

Figure 8: Droplet survival or shattering behaviour as a function of We and Oh

Figure 9: Framework for the formation of liquid marbles via the mechanical dispersion regime

Figure 10: Combined framework for the formation of liquid marbles via the droplet template and mechanical dispersion regime

Figure 11: Framework for formation of hollow granules from liquid marbles 


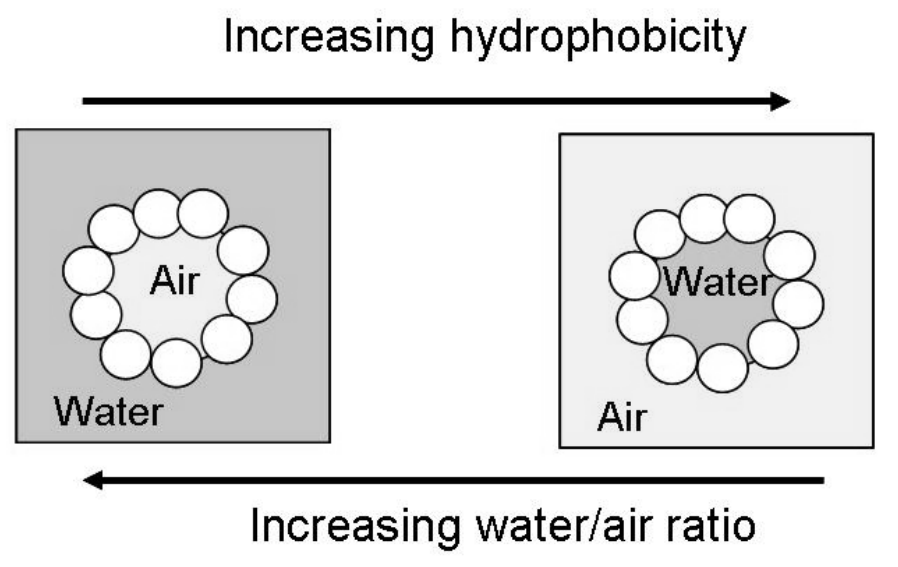

Figure 1 
Figure 2

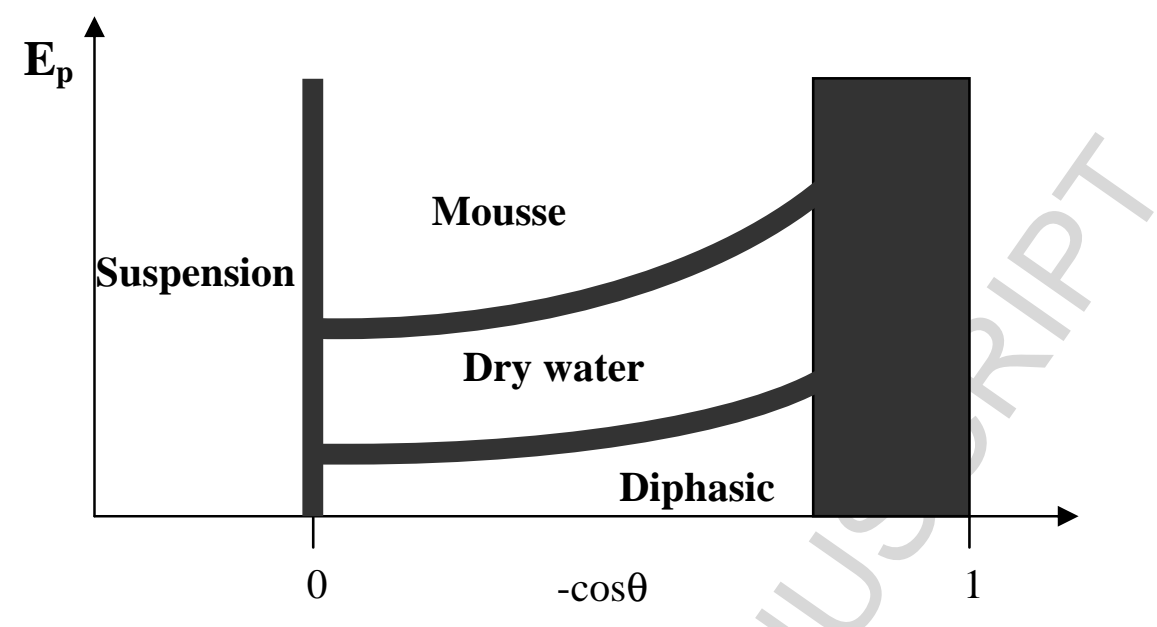




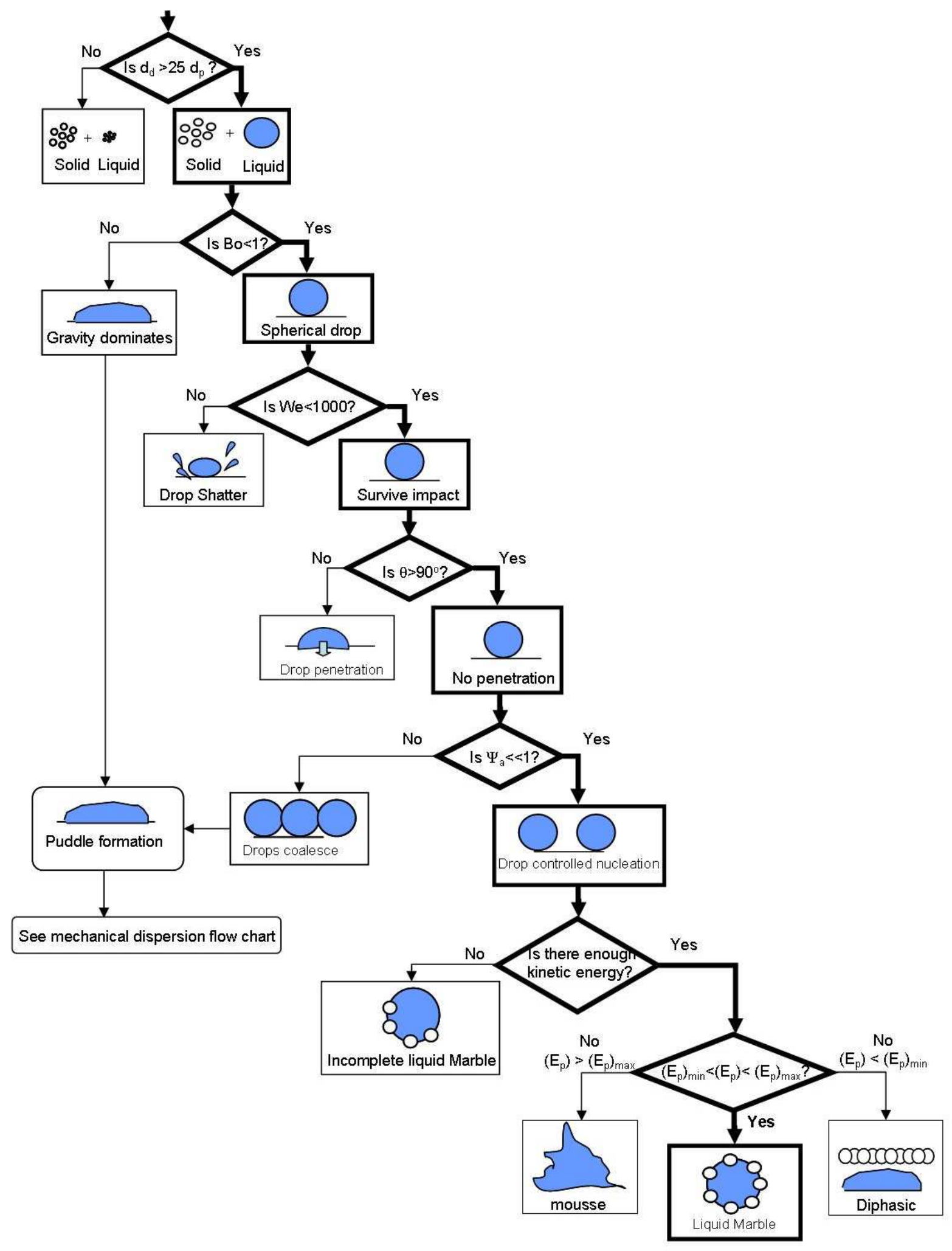

Figure 3 


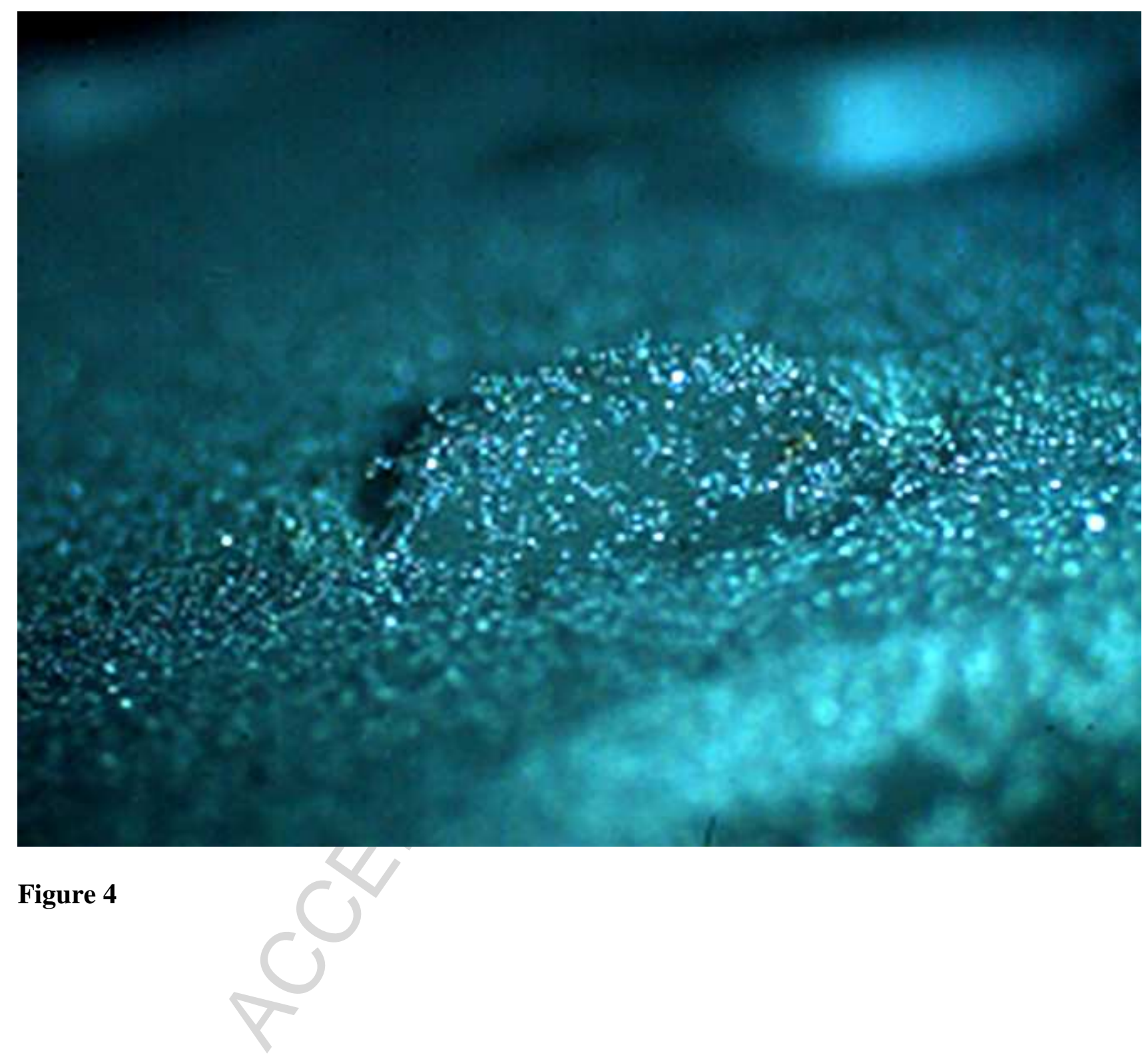




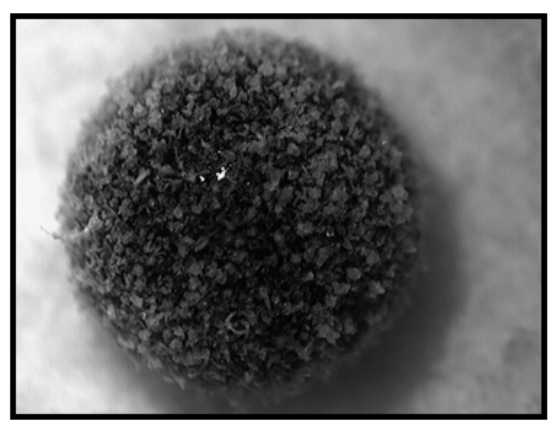

(a)

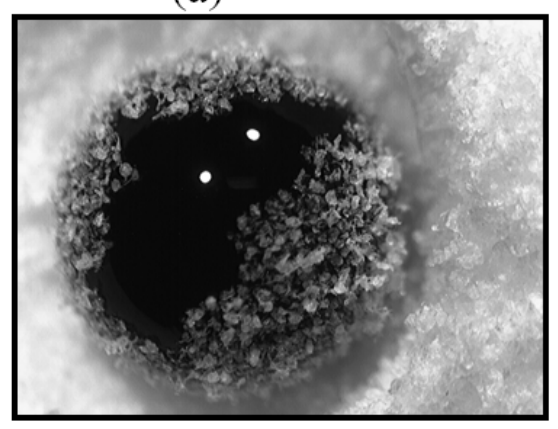

(d)

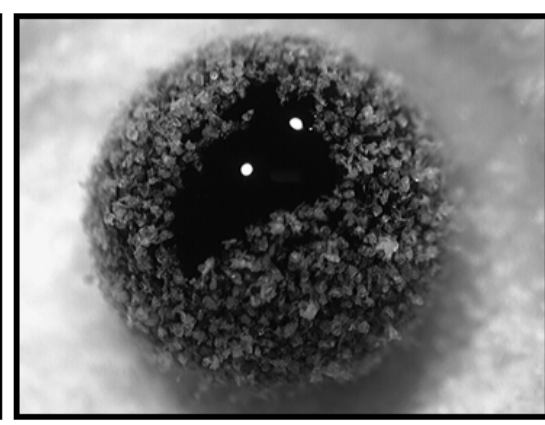

(b)

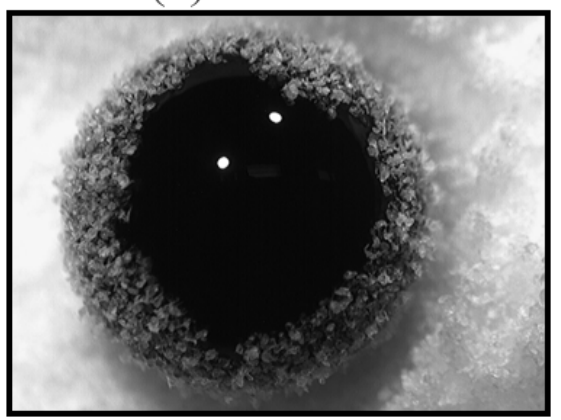

(e)

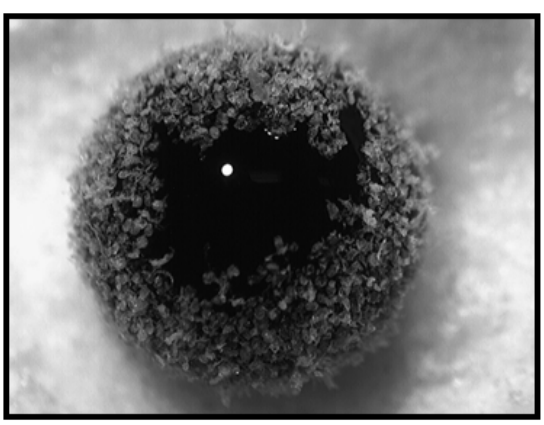

(c)

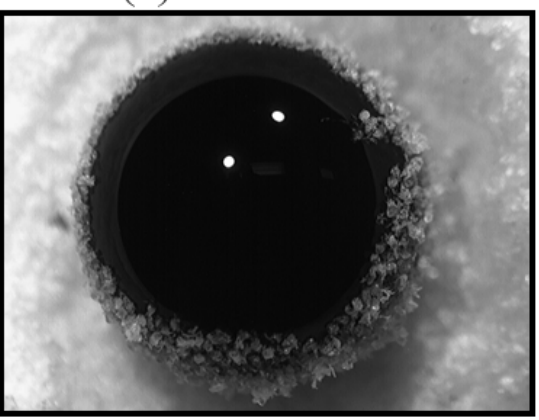

(f)

Figure 5 


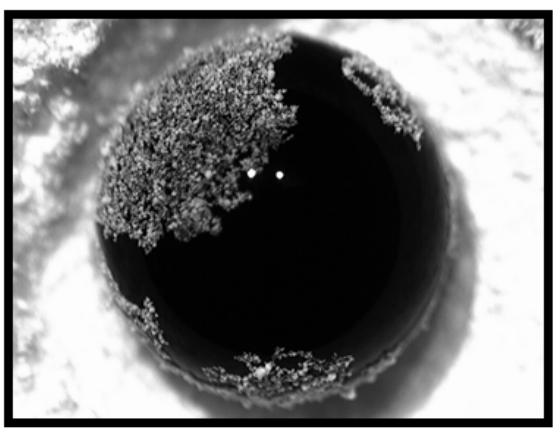

(a)

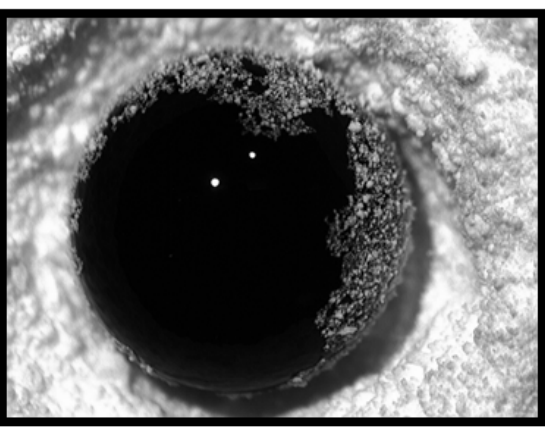

(b)

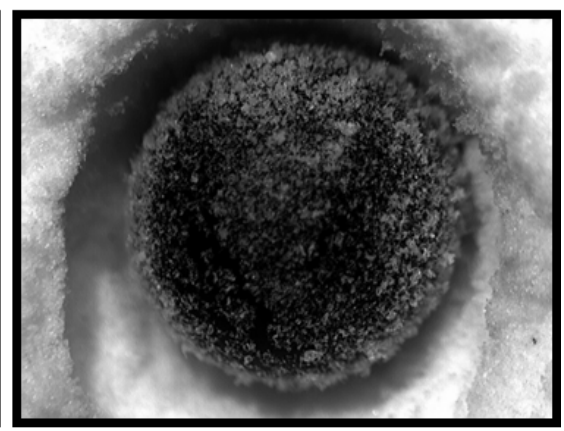

(c)

Figure 6 

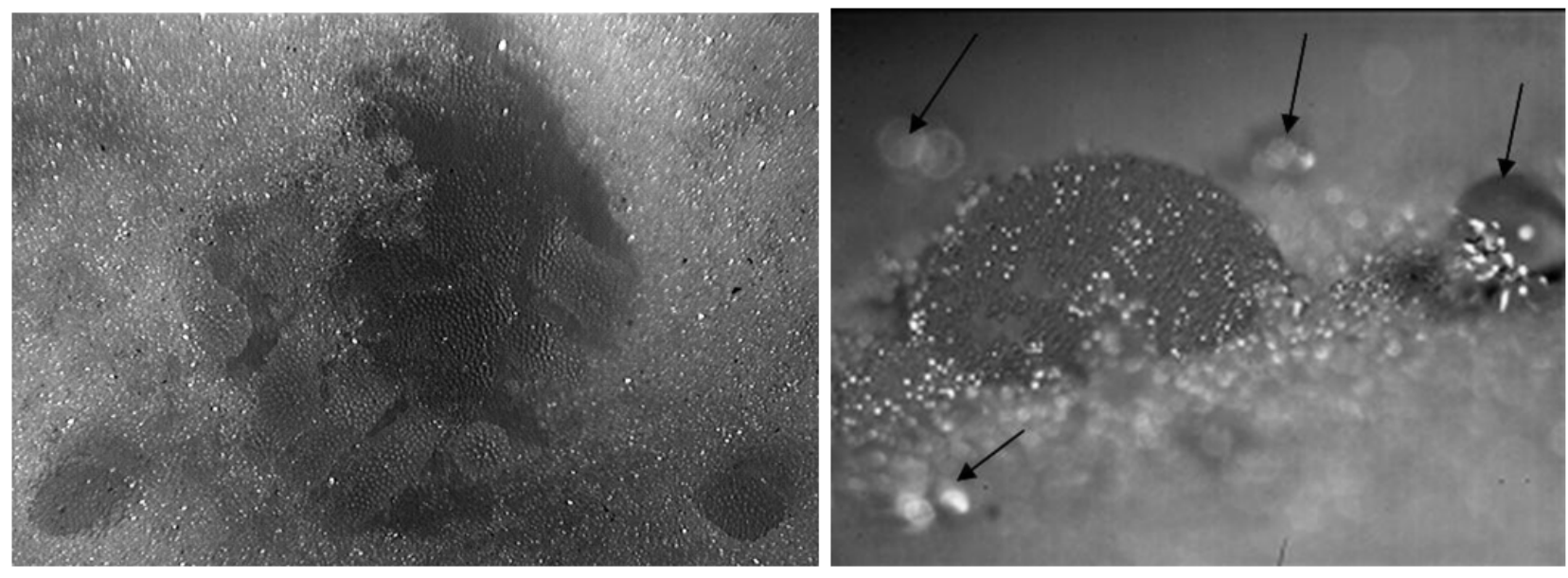

Figure 7

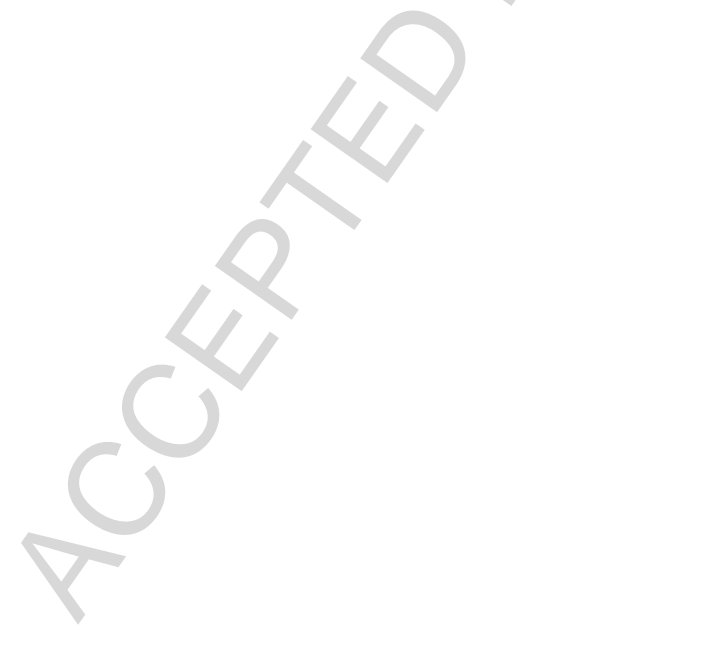




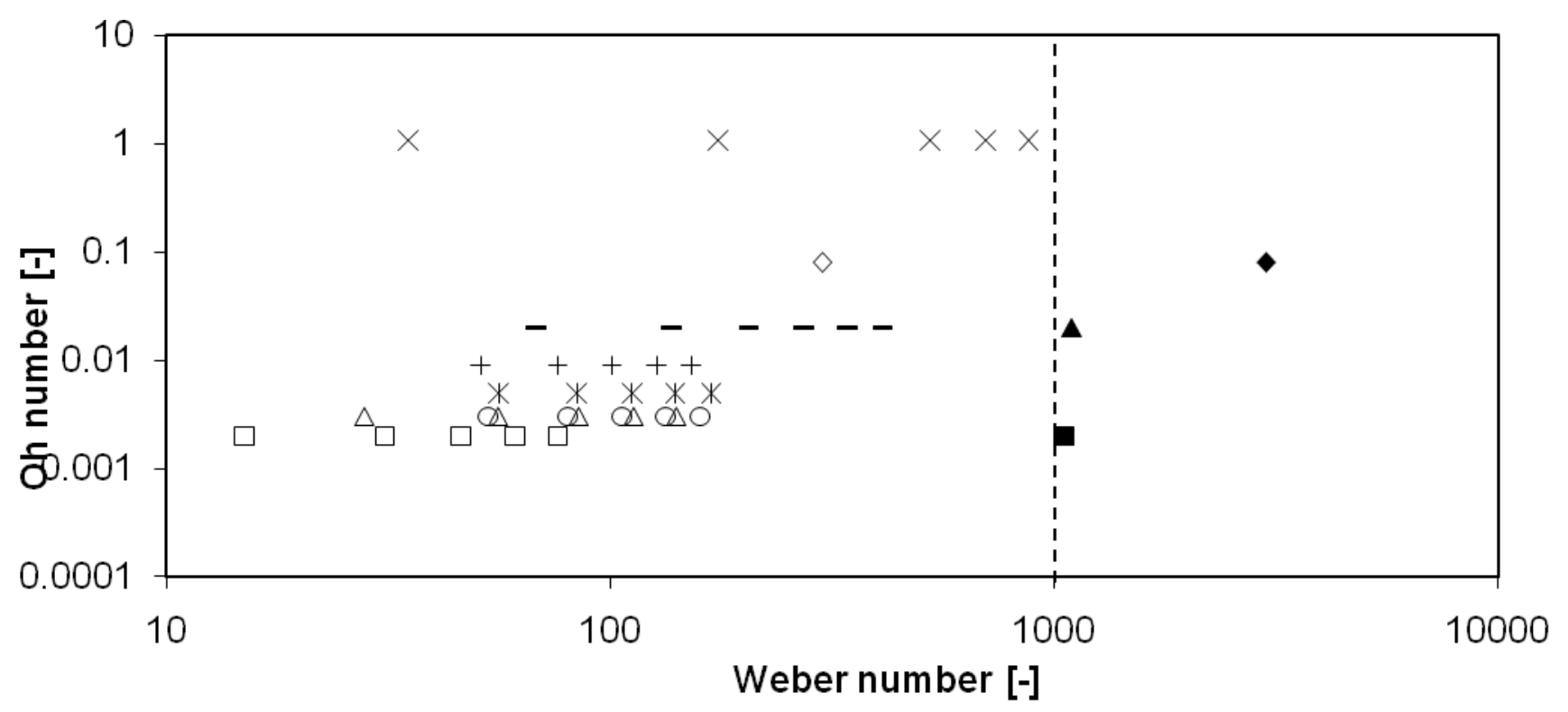

Water droplet on PTFE 1, 12, 35

Water droplet on PTFE 100

$80 \%$ glycerol droplet on glass beads

O $20 \%$ glycerol droplet on PTFE 100

* $40 \%$ glycerol droplet on PTFE 100

Water droplet on PTFE 100 and glass beads

$+60 \%$ glycerol droplet on PTFE 100

$-80 \%$ glycerol droplet on PTFE 100

Water droplet on glass beads $($ release height $=15 \mathrm{~cm}) \times 100 \%$ glycerol droplet on PTFE 100

Water droplet on glass beads (release height $=80 \mathrm{~cm}$ )

\section{Figure 8}




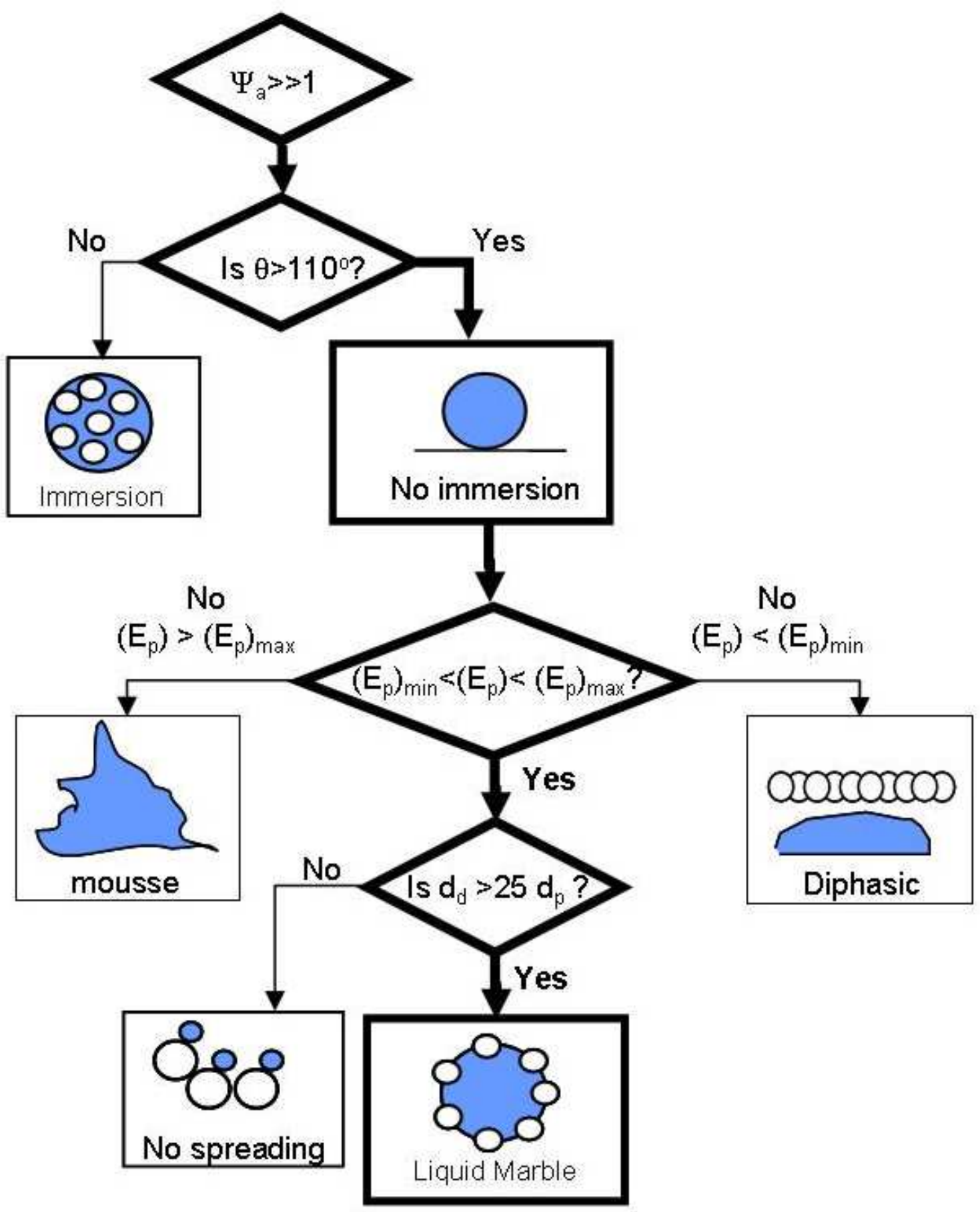

Figure 9 


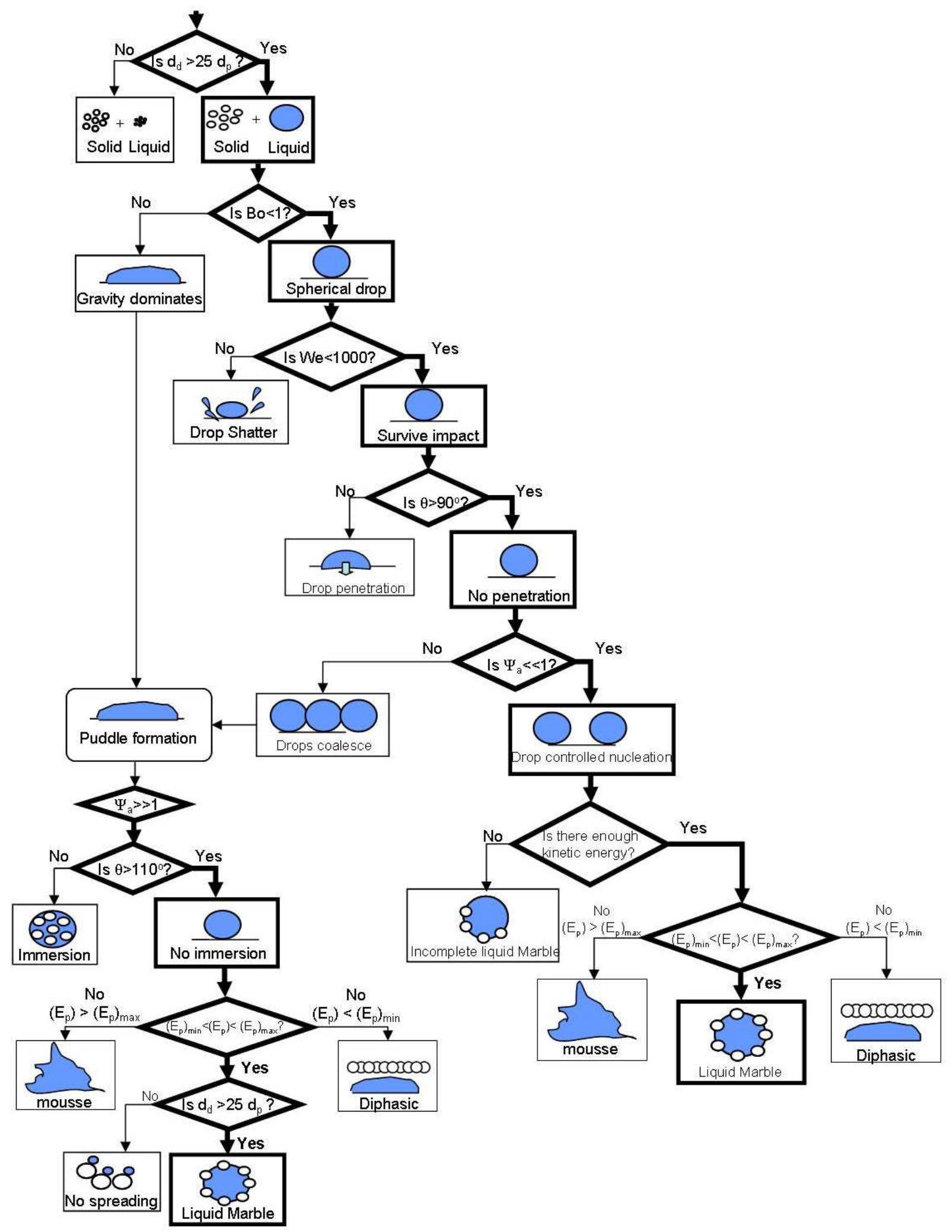

Figure 10 


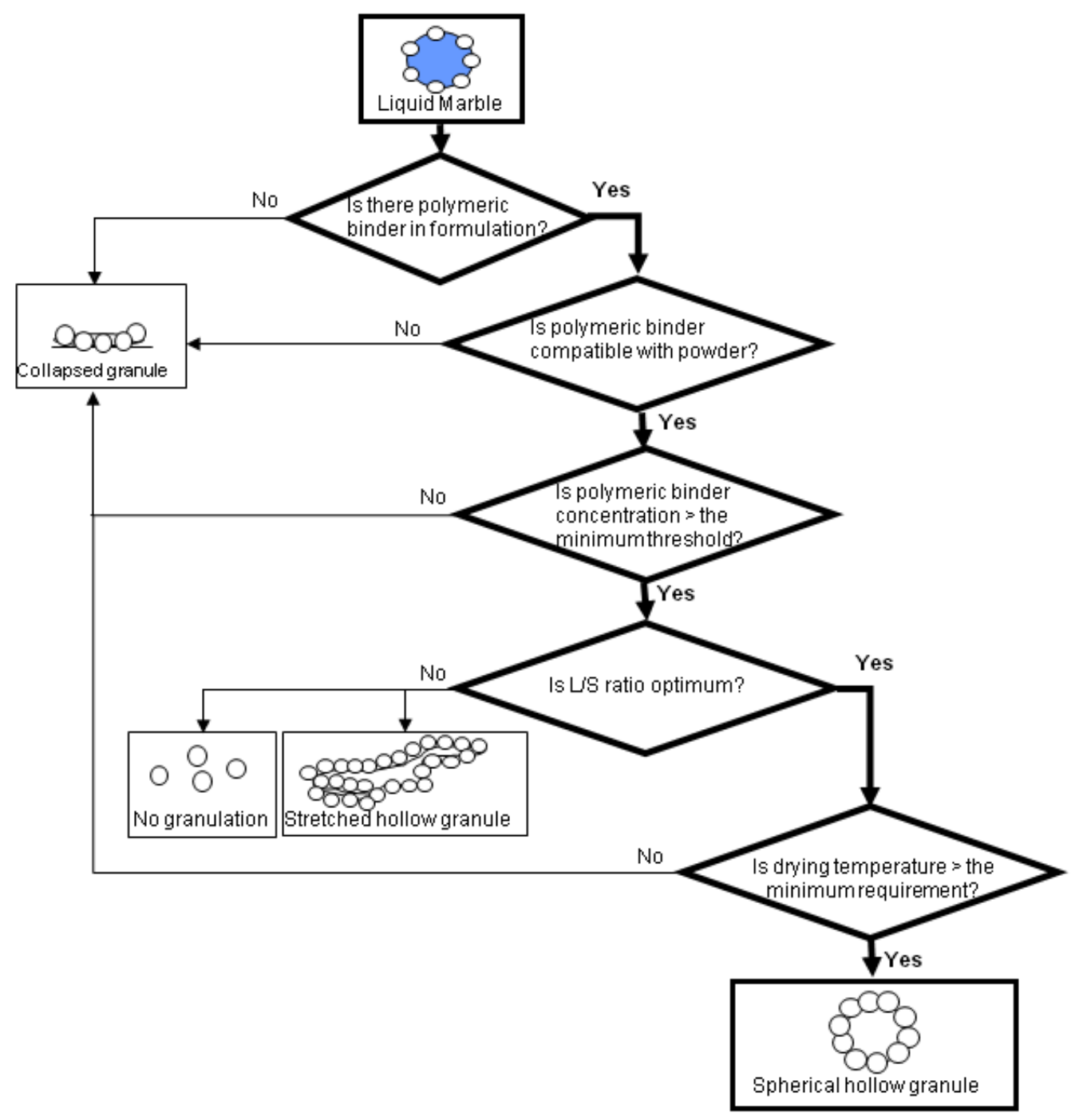

Figure 11 
Table 1: Droplet and particle size value for liquid marble formation

\begin{tabular}{|c|c|c|c|c|c|}
\hline Powder & Fluid & $\begin{array}{l}\text { Particle } \\
\text { diameter } \\
\left(\mathrm{d}_{\mathrm{p}}, \mu \mathrm{m}\right) \\
\end{array}$ & \begin{tabular}{c|} 
Droplet \\
diameter \\
$\left(\mathrm{d}_{\mathrm{d}}, \mu \mathrm{m}\right)$ \\
\end{tabular} & $\begin{array}{l}\text { Droplet diameter } \\
\text { /Particle diameter } \\
\qquad\left(\mathrm{d}_{\mathrm{d}} / \mathrm{d}_{\mathrm{p}}\right)\end{array}$ & $\begin{array}{l}\text { Liquid } \\
\text { marble? }\end{array}$ \\
\hline \multicolumn{6}{|c|}{ Small scale experiment $[26,36]$} \\
\hline Aerosil & \multirow{6}{*}{$\begin{array}{l}\text { Water or } \\
\text { Glycerol }\end{array}$} & 0.01 & & 340000 & \multirow{6}{*}{ Yes } \\
\hline PTFE 1 & & 1 & & 3400 & \\
\hline PTFE 12 & & 12 & & 283 & \\
\hline PTFE 35 & & 35 & & 97 & \\
\hline PTFE 100 & & 100 & & 34 & \\
\hline Hydrophobic glass bead (AG/AH) & & 65 & & 52 & \\
\hline PTFE 1 & \multirow{4}{*}{ PEG 200} & 1 & \multirow{4}{*}{2580} & 2580 & \multirow{4}{*}{ Yes } \\
\hline PTFE 12 & & 12 & & 215 & \\
\hline PTFE 35 & & 35 & & 74 & \\
\hline PTFE 100 & & 100 & & 26 & \\
\hline Hydrophobic glass bead (AH) & PEG 200 & 65 & 2580 & 40 & Yes \\
\hline Hydrophobic glass bead (AE) & PEG 200 & 121 & 2580 & 21 & No \\
\hline Hydrophobic glass bead (AC) & PEG 200 & 191 & 2580 & 14 & No \\
\hline \multicolumn{6}{|c|}{ Large scale experiment [20] } \\
\hline Aerosil & $5 \% \mathrm{HPC}$ & 0.01 & 442 & 44200 & Yes \\
\hline \multicolumn{6}{|c|}{ Literature data } \\
\hline PTFE [25] & $\begin{array}{l}\text { Water or } \\
\text { Glycerol }\end{array}$ & $7-12$ & 1200 & $100-170$ & Yes \\
\hline Aerosil [25] & $\begin{array}{l}\text { Water or } \\
\text { Glycerol }\end{array}$ & 0.01 & 1200 & 120000 & Yes \\
\hline Lycopodium [1] & Water & 20 & 2000 & 100 & Yes \\
\hline Graphite micro powder [14] & Water & $2-30$ & 2000,4000 & $67-2000$ & Yes \\
\hline Aerosil [35] & Water & $0.02-0.03$ & $50-400$ & $2500-20000$ & Yes \\
\hline$N$ & $\begin{array}{l}\text { Water \& } \\
\text { Ionic liquid }\end{array}$ & 35 & 1280 & 37 & Yes \\
\hline OTFE [19] & $\begin{array}{l}\text { Water \& } \\
\text { Ionic liquid }\end{array}$ & 35 & 1280 & 37 & Yes \\
\hline \multirow{2}{*}{$\begin{array}{l}\text { Hydrophobic copper powder [32] } \\
\text { Poly-methylmethacralate } \\
\text { (PMMA) [32] }\end{array}$} & \multirow[t]{2}{*}{ Water } & $\begin{array}{c}9 \\
15\end{array}$ & 2000 & $\begin{array}{l}220 \\
130\end{array}$ & Yes \\
\hline & & 320 & 2000 & 6 & No* \\
\hline Aerosil [21] & Water & 0.01 & 2000 & 200000 & Yes \\
\hline PTFE [25] & Water & 0.016 & 80 & 5000 & Yes \\
\hline
\end{tabular}

* Maximum coverage of liquid marble was $60-70 \%$. 
Table 2: Summary of drop impact and shattering experiments.

\begin{tabular}{|c|c|c|c|c|c|c|c|}
\hline Fluid & Powder & $\begin{array}{c}\text { Height } \\
\text { (cm) }\end{array}$ & $\begin{array}{c}\text { Drop } \\
\text { diameter } \\
(\mathbf{m m})\end{array}$ & We \# & Oh \# & Bo \# & Shattered? \\
\hline Water & Hydrophobic glass bead (AG) & 15 & 3 & $\sim 300$ & 0.08 & 0.3 & No \\
\hline Water & Hydrophobic glass bead (AG) & 80 & 3 & $\sim 3000$ & 0.08 & 0.3 & Yes \\
\hline \multirow{5}{*}{$\begin{array}{l}\text { Water \& } \\
\text { dye }\end{array}$} & \multirow[t]{5}{*}{ PTFE $1,12,35$} & 2.5 & & 28 & \multirow{5}{*}{0.003} & \multirow{5}{*}{0.48} & \multirow{5}{*}{ No } \\
\hline & & 5 & & 56 & & & \\
\hline & & 7.5 & 3.4 & 85 & & & \\
\hline & & 10 & & 113 & & & \\
\hline & & 12.5 & & 141 & & & \\
\hline \multirow{7}{*}{$\begin{array}{l}\text { Water \& } \\
\text { dye }\end{array}$} & \multirow[t]{6}{*}{ PTFE 100} & 2 & & 15 & \multirow{6}{*}{0.002} & \multirow{6}{*}{0.48} & \multirow{5}{*}{ No } \\
\hline & & 4 & & 31 & & & \\
\hline & & 6 & & 46 & & & \\
\hline & & 8 & & 61 & & & \\
\hline & & 10 & & 76 & & & \\
\hline & & 92 & & 1050 & & & Yes \\
\hline & Hydrophobic glass bead (AH) & 92 & 3.4 & 1050 & 0.002 & 0.48 & Yes \\
\hline \multirow{5}{*}{$\begin{array}{l}20 \% \\
\text { Glycerol } \\
\& \text { dye }\end{array}$} & \multirow[t]{5}{*}{ PTFE 100} & 5 & \multirow{5}{*}{3.4} & 53 & \multirow{5}{*}{0.003} & \multirow{5}{*}{0.5} & \multirow{5}{*}{ No } \\
\hline & & 7.5 & & 80 & & & \\
\hline & & 10 & & 106 & & & \\
\hline & & 12.5 & & 133 & & & \\
\hline & & 15 & & 159 & & & \\
\hline \multirow{5}{*}{$\begin{array}{l}40 \% \\
\text { Glycerol } \\
\& \text { dye }\end{array}$} & \multirow[t]{5}{*}{ PTFE 100} & 5 & \multirow{5}{*}{3.4} & 56 & \multirow{5}{*}{0.005} & \multirow{5}{*}{0.54} & \multirow{5}{*}{ No } \\
\hline & & 7.5 & & 84 & & & \\
\hline & & 10 & & 112 & & & \\
\hline & & 12.5 & & 140 & & & \\
\hline & & 15 & & 169 & & & \\
\hline \multirow{5}{*}{$\begin{array}{l}60 \% \\
\text { Glycerol } \\
\& \text { dye }\end{array}$} & PTFE 100 & 5 & & 51 & & & \\
\hline & ( & 7.5 & & 76 & & & \\
\hline & $\infty$ & 10 & 3.4 & 101 & 0.009 & 0.58 & No \\
\hline & V & 12.5 & & 127 & & & \\
\hline & 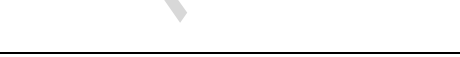 & 15 & & 152 & & & \\
\hline $80 \%$ & PTFE 100 & 5 & & 68 & & & \\
\hline Glycerol & & 10 & & 137 & & & \\
\hline$\&$ dye & & 15 & & 205 & & & \\
\hline & & 20 & 3.4 & 273 & 0.02 & 0.6 & No \\
\hline & & 25 & & 342 & & & \\
\hline & & 30 & & 411 & & & \\
\hline & Hydrophobic glass bead (AH) & 75 & & 1094 & & & Yes \\
\hline $100 \%$ & PTFE 100 & 5 & & 175 & & & \\
\hline Glycerol & & 10 & & 35 & & & \\
\hline \& dye & & 15 & 3.4 & 525 & 1.08 & 0.88 & No \\
\hline & & 20 & & 701 & & & \\
\hline & & 25 & & 876 & & & \\
\hline
\end{tabular}


Table 3: Contact angle values for several powders with water

\begin{tabular}{lll}
\hline Powder & Contact angle $\left.\mathbf{(}^{\mathbf{0}}\right)$ & Reference \\
\hline PTFE & 140 & {$[37]$} \\
OTFE & 177 & {$[9]$} \\
Aerosil R972 & 103 & {$[27]$} \\
Aerosil R812S & 113 & {$[27]$} \\
Aerosil R202 & $>113$ & {$[27]$} \\
Hydrophobic copper powder & 157 & {$[25]$} \\
Poly-methylmethacralate (PMMA) & 120 & {$[25]$} \\
Lycopodium powder & $>150$ & {$[2]$} \\
Graphite micro powder & $145-160$ & {$[5]$} \\
\hline
\end{tabular}

Table 4: Optimum L:S ratio in different studies of hollow granule formations

\begin{tabular}{lll}
\hline Investigated range of L:S ratio & Optimum L:S & Reference \\
\hline $0.7-0.78: 1$ & $0.74: 1$ & {$[12]$} \\
$0.5-15: 1$ & $3: 1-6: 1$ & {$[10]$} \\
$33: 1$ & Not reported & {$[3]$} \\
\hline
\end{tabular}

